\title{
Epidemiology of special incidents: Results from national mortality and morbidity registry and the associated factors in Iran in $\mathbf{2 0 1 4}$
}

\author{
Javad Bazeli ${ }^{1}$, Aidin Aryankhesal ${ }^{2,3}$, Davoud Khorasani-Zavareh ${ }^{4,5,6}$
}

${ }^{1}$ Ph.D. Student of Health in Disasters and Emergencies, School of Health Management and Information Sciences, Iran University of Medical Sciences, Tehran, Iran

${ }^{2}$ Ph.D. in Health Policy and Management, Associate Professor, Health Management and Economics Research Center, Iran University of Medical Sciences, Tehran, Iran

${ }^{3}$ Ph.D. in Health Policy and Management, Associate Professor, Department of Health Services Management, School of Health Management and Information Sciences, Iran University of Medical Sciences, Tehran, Iran

${ }^{4}$ Ph.D. in Safety Promotion and Injury Prevention, Associate Professor, Safety Promotion and Injury Prevention Research Center, Shahid Beheshti University of Medical Sciences, Tehran, Iran

${ }^{5} \mathrm{Ph} . \mathrm{D}$. in Safety Promotion and Injury Prevention, Associate Professor, Department of Health in Disaster and Emergency, School of Health, Safety and Engineering, Shahid Beheshti University of Medical Sciences, Tehran, Iran

${ }^{6}$ Ph.D. in Safety Promotion and Injury Prevention, Associate Professor, Department of Clinical Science and Education, Karolinska Institute, Stockholm, Sweden

\section{Type of article: Original}

\begin{abstract}
Background: Special incidents are harmful events that can result in people's death or injury. Despite registering special incidents' data in Iran, no study has yet been conducted to identify the types, rates, mortality and morbidity of such incidents and their associated factors. The present study was conducted to assess the epidemiology of incidents and their associated factors during 2014 in Iran.

Methods: In this cross-sectional study, all special incidents of 2014 were examined. Data were initially collected by universities of medical sciences nationwide and then sent to the Disaster and Emergency Management Center in the Ministry of Health and Medical Education. The collected data were analyzed in this study using statistical tests of Chi-square and Pearson's correlation coefficient using SPSS ver. 14.5.

Results: Out of 6,892 special incidents that occurred during 2014 in Iran, 6,781 cases were included, of which, the most prevalent were traffic crashes $(71 \%)$, carbon monoxide poisoning $(14 \%)$, drowning $(3.5 \%)$, and other cases (11.5\%) (which included suspicious deaths, explosions, group poisoning, quarrels, fires, falls from height, and building collapses). The incidents led to 37,313 injuries and 3,259 deaths, of which $78 \%$ of injuries and $75 \%$ of deaths were due to road traffic incidents.

Conclusion: Given to relationship between occurrence of the incidents and special holidays; such incidents can be reduced through preventive planning and education. We recommend annual monitoring of special incidents and further studies on the associated factors.

Keywords: Traffic Accidents; Special Incidents; Mass-Casualty Incidents; Mortality; Morbidity
\end{abstract}

\section{Introduction}

Rapid economic development and increasing population lead to increased man-made incidents such as road traffic incidents (RTIs), spillage of chemicals, building collapses, explosions in factories, widespread food poisoning, and other high-casualty incidents (1). In recent decades, mass-casualty incidents have frequently occurred in low and

\section{Corresponding author:}

Associate Professor Dr. Aidin Aryankhesal, Iran University of Medical Sciences, Tehran, Iran.

Tel: +98.2188773073, Fax:+98.2188883334, Email: aryankhesal.a@iums.ac.ir

Received: March 16, 2017, Accepted: June 20, 2017, Published: August 2017

iThenticate screening: June 17, 2017, English editing: July 28, 2017, Quality control: August 05, 2017

This article has been reviewed / commented by three experts

(C) 2017 The Authors. This is an open access article under the terms of the Creative Commons Attribution-NonCommercialNoDerivs License, which permits use and distribution in any medium, provided the original work is properly cited, the use is non-commercial and no modifications or adaptations are made. 
middle-income countries and affected great numbers of people. Such incidents may disrupt plans and services of health sectors, or hinder sustainable development of societies (2). A mass-casualty incident is defined as one in which the number of resulting casualties cannot be managed with the current facilities and resources and usual operational processes of organizations (2). Hence, a mass-casualty event is defined differently according to available resources in different countries and areas. For example, in New York, mass-casualty incidents are referred to those involving more than five casualties (3). In Pakistan, any incident with more than three casualties is called a masscasualty event (4). According to another definition, events leading to injury of large numbers of people whose needs cannot be met by available resources are called mass-casualty incidents (5). In Iran, no acceptable definition has yet been proposed by experts for mass-casualty events, and such events may have different definitions in different organizations. For instance, according to the National Disaster and Emergency Management Center (NDEMC), any road traffic incident resulting in at least three deaths or at least five injuries, is referred to as a mass-casualty incident (6). Apart from mass-casualty incidents, some incidents can be of high importance, although they may lead to no or little casualty. The importance given to the incidents depend on any nation's health, social, geographical or political context. Such events and emergencies, in Iran, should be immediately reported to the Emergency Operation Center (EOC) of the Ministry of Health and Medical Education (MoHME), within 3 hours of occurrence. Iran's Ministry of Health and the MoHME referred to such events as "special events" (7). All mass casualty incidents are special incidents, but not vice versa. Unofficial evidence suggests that RTIs are currently the leading type of unintentional injury in Iran $(6,8)$. Iran, with 34.1 deaths per 100,000 people in $2013(9)$ and 32.1 deaths per 100,000 people and 304,485 injured cases in 2014 (10), has one of the highest mortality rates due to RTI in the world (11), and these injuries are believed to be the second leading cause of death and the leading cause of loss of life $(12,13)$. Moreover, RTI alone in Iran accounted for damages of 2,952 billion Rials (about 90 million USD) in 2009, and 39 billion USD in $2013(12,14)$. Since no study has yet been conducted on special incidents in Iran, the present study was conducted with the aim to investigate epidemiology of special incidents during 2014 and to determine their epidemiological pattern and related factors. Analysis of these data may pave the way for preventive planning and policy-making in relation to incidence of such events.

\section{Material and Methods}

\subsection{Study area and setting}

This is a cross-sectional study that was conducted on all special incidents reported by the EOC of the MoHME. The incidents happened between 21 March 2014 and 20 March 2015, which is one complete Iranian calendar year as 1393. Iran is a Middle-Eastern country with an area of 1,648,195 square kilometers (8), and a relatively young population of more than 75 million ( $50.4 \%$ male and $49.6 \%$ female), such that $60.1 \%$ of the population are in the 15 to 49 years age group, and $72.8 \%$ of the population live in urban areas (15). The annual population growth rate is $1.3 \%$. Iran has 31 provinces, 429 towns, different ethnicities, dry and warm climate and expansive deserts. In the present study, data of all special incidents, as defined by the EOC (7) that occurred during the above-mentioned dates, from now on referred to as 2014 for ease of use, were analyzed. The Disaster and Emergency Management Center is a subset of the Deputy of Treatment in the MoHME that is responsible for policy-making, coordinating, planning, and monitoring the EOCs across the country $(16,17)$, and providing pre-hospital emergency services (First Aid). To optimize management of various events, this center has been divided into nine different poles affiliated to one of the universities of medical sciences as the center, so that decentralized countrywide rescue services can be provided (18). According to the guidelines provided by MoHME, 22 cases were defined as special incidents, including 1) RTIs involving more than four casualties; 2) RTIs resulting in more than two deaths; 3 ) landmine explosion; 4) any protest or demonstration; 5) riots; 6) aviation events such as airplane or helicopter crash; 7) shooting cases involving casualty or death; 8) group poisoning affecting four or more people; 9) air and water pollutions; 10) natural disasters such as floods and earthquakes; 11) suicide-related deaths; 12) terrorism; 13) hostage; 14) incidents relating to special sites such as sacred, political and military sites; 15) death or injury of local elites; 16) incidents involving transportation, manufacture, or storage of hazardous materials; 17) multi-vehicle collisions with or without deaths or injuries; 18) environmental or occupational health crashes; 19) CO poisoning; 20) suspicious deaths; 21) nuclear and biological incidents; and recently, 22) incidents involving health sector personnel at work (7).

\subsection{Database and data collection procedure}

The main data from these crashes are faxed to local EOC and the MoHME's EOC within three hours of occurrence on standard forms approved by the NDEMC. All these data are then recorded in the center's database on an Excel file by EOC personnel working around the clock. After obtaining necessary permission, all data relating to incidents during 2014 were obtained on an Excel file. These data included type, date and time of the incident, province of the 
incident, number of casualties, number of ambulances dispatched, Emergency Management System (EMS) response time (from emergency call to ambulance arrival time on the scene), number of deaths (before ambulance arrival, in presence of emergency technician, during transfer to hospital, and in the hospital), number of casualties transferred to hospital, number of minor injured casualties (not requiring transfer to hospital and discharged after outpatient care on the scene) for each incident.

\subsection{Ethics}

Ethics committee approval of Iran University of Medical Sciences (No: 94.D.105.4886 / 28.oct.2014) was taken, and permission was also obtained from official authorities.

\subsection{Dataset clean up}

A total of 6,892 cases of special incidents occurred across Iran during 2014 and reported to the EOC of MoHME, of which 111 cases were not publishable due to ethical and legal considerations, and thus, study was conducted on 6,781 cases. To confirm validity of data, $1 \%$ of data were cross-checked with those of the relevant university EOCs; we found the same results in survey dataset. Then, data were entered into Statistical Package for Social Science (SSPS) ver. 14.5 software. Mean times were worked out in minutes, and the relationships between variables such as type of incident, incidence interval, months, and seasons were analyzed using Chi-square test and Pearson's correlation coefficient. All statistical significances were at $\mathrm{p}$-values less than 0.05 .

\subsection{Data treatment}

Findings were categorized based on type (RTI, CO poisoning, explosion, suspicious death, group poisoning, drowning, falls from heights, group quarrel, fire, and building collapse), week days, month and season, holidays and special holidays (weekends, official holidays, Nowruz holidays), hours of the day (four intervals including 00.00$5.59,6.00-11.59,12.00-17.59,18.00-23.59$ ), and province of incident. Next, distribution of incidents was extracted as descriptive data including absolute and relative frequencies, mortality and injuries of each type, their prevalence on special occasions (week days, special holidays, and Nowruz holidays), their distribution according to time of day

and seasons, distribution across the country and provinces, emergency response time to the events, distribution of incidents in different provinces and population ratio.

\section{Results}

Special incidents during 2014 led to 3,259 deaths, 37,313 casualties, from which there were 3,447 hospitalized casualties, and 3,866 cases of minor injuries (outpatient treatment on the scene). In response to these incidents, a total of 12,634 ambulances were deployed, and mean response time was 8 minutes $( \pm 6: 00)$. Out of total cases studied, $71 \%$ were RTI with more than two deaths or four injuries, $14 \%$ CO poisoning cases, $3.5 \%$ drowning, and $11.5 \%$ other cases, which included suspicious deaths, explosions, group poisoning, quarrels, fire, falls from heights, and building collapses. RTIs were the most casualties (29,190; mean 6 casualties per accident) followed by CO poisoning with 2,619 casualties (2.7 per incident) (Table 1). Most incidents occurred in Fars province (13\%), followed by Mazandaran (8\%), and the least in North Khorasan (42 cases or 0.6\%) (Figure 1). In terms of seasonal distribution, no particular difference was found in the crude distribution of incidents (given their diversity), so that most incidents occurred in summer (26\%), followed by winter with a small difference (25.5\%) (Table 2). However, distribution of different incidents was different depending on the season. RTIs were the most prevalent incidents in all seasons, but their pattern varied according to the season, such that they were most prevalent during summer with 1,447 cases ( $81 \%$ of total incidents in that season, and $30 \%$ of all RTIs), while 995 RTIs happened in winter (57\% of total incidents in winter, and $21 \%$ of total RTIs). CO gas poisoning was most prevalent in winter (with 508 cases, $29 \%$ of all winter incidents, and $53 \%$ of total CO poisoning cases), and least prevalent in summer (with 10 cases, $8 \%$ of summer incidents, and $1 \%$ of total poisoning cases). With 140 cases, drowning mostly occurred in summer $(8 \%$ of summer incidents, and $50 \%$ of total drowning cases), and least in winter with 8 cases ( $4 \%$ of all drowning cases). Chi-square test showed a significant relationship between type of incident and season $(\mathrm{p}<0.001)$. In terms of timing of incidents, more than one third occurred during 12.00-17.59, 29\% during 18.00-23.59, 23\% during 6.00-11.59, and $13 \%$ during 00.00-5.59. Chi-square test indicated a significant relationship between timing of incidents and their occurrence $(\mathrm{p}<0.001)$. Distribution of incidents during week days also followed a pattern; Fridays had the most incidents (1,359 cases) and Mondays the least (787 cases). The number of incidents increased from Monday to Friday $(\mathrm{r}=0.933, \mathrm{p}=0.021$, Pearson Correlation). Chi-square test also showed a significant relationship between occurrence of incidents and week days $(\mathrm{p}=0.005)$. In terms of crude occurrence of special incidents during holidays and working days, the majority occurred on working days (55\%) followed by Thursdays and Fridays (34\%), and the least on official holidays (4\%) and Nowruz holidays (7\%). When occurrence of these incidents is arranged according 
http://www.ephysician.ir

to the number of relevant days, Table 3 is obtained. Table 3 shows that the least incidents occurred on working days ( 15 cases per day), and the most on Nowruz holidays ( 77 cases per day). The same applies to special RTIs, which peaked in Nowruz, about 5.1 times as working days.

Table 1. Frequency of special incidents by the type of incident, number of injured and dead, Iran in 2014

\begin{tabular}{|l|l|l|l|l|l|l|l|}
\hline Event type & $\begin{array}{l}\text { Incident; } \\
(\%)\end{array}$ & $\begin{array}{l}\text { Death; } \mathrm{n} \\
(\%)\end{array}$ & $\begin{array}{l}\text { Injuries; } \mathrm{n}(\%) \\
\text { Major }\end{array}$ & Minor & Death; $\mathrm{n}$ (\%) & $\begin{array}{l}\text { During transfer to } \\
\text { hospital }\end{array}$ & $\begin{array}{l}\text { At } \\
\text { hospital }\end{array}$ \\
\hline $\begin{array}{l}\text { Road traffic } \\
\text { incidents }\end{array}$ & $4812(70.9)$ & $\begin{array}{l}2459 \\
(75.4)\end{array}$ & $\begin{array}{l}27677 \\
(82.7)\end{array}$ & $\begin{array}{l}1513 \\
(39.1)\end{array}$ & $\begin{array}{l}2250 \\
(74.8)\end{array}$ & $74(97.4)$ & $\begin{array}{l}135 \\
(77.6)\end{array}$ \\
\hline CO poisoning & $961(14.2)$ & $191(5.9)$ & $\begin{array}{l}2065 \\
(6.2)\end{array}$ & $\begin{array}{l}554 \\
(14.3)\end{array}$ & $\begin{array}{l}190 \\
(6.3)\end{array}$ & $0(0)$ & $1(0.6)$ \\
\hline Explosion & $163(2.4)$ & $53(1.6)$ & $479(1.4)$ & $38(1)$ & $46(1.5)$ & $0(0)$ & $7(4)$ \\
\hline $\begin{array}{l}\text { Unexplained } \\
\text { death }\end{array}$ & $186(2.7)$ & $199(6.1)$ & $8(0)$ & $0(0)$ & $\begin{array}{l}193 \\
(6.4)\end{array}$ & $1(1.3)$ & $5(3)$ \\
\hline Drowning & $236(3.5)$ & $180(5.5)$ & $129(0.4)$ & $16(0.4)$ & $\begin{array}{l}169 \\
(5.6)\end{array}$ & $0(0)$ & $11(6.3)$ \\
\hline Group poisoning & $139(2)$ & $22(0.7)$ & $\begin{array}{l}2243 \\
(6.7)\end{array}$ & $\begin{array}{l}1511 \\
(39)\end{array}$ & $17(0.6)$ & $0(0)$ & $5(3)$ \\
\hline Fall from height & $45(0.7)$ & $38(1.2)$ & $72(0.2)$ & $4(0.1)$ & $36(1.2)$ & $1(1.3)$ & $1(0.6)$ \\
\hline Fire & $92(1.4)$ & $45(1.4)$ & $233(0.7)$ & $113(3)$ & $42(1.4)$ & $0(0)$ & $3(1.3)$ \\
\hline Quarrel & $94(1.4)$ & $31(0.9)$ & $398(1.2)$ & $113(3)$ & $26(0.9)$ & $0(0)$ & $5(3)$ \\
\hline Building collapse & $53(0.8)$ & $41(1.3)$ & $143(0.5)$ & $4(0.1)$ & $40(1.3)$ & $0(0)$ & $1(0.6)$ \\
\hline Total & $6781(100)$ & $\begin{array}{l}3259 \\
(100)\end{array}$ & $\begin{array}{l}33447 \\
(100)\end{array}$ & $\begin{array}{l}3866 \\
(100)\end{array}$ & $\begin{array}{l}3009 \\
(100)\end{array}$ & $76(100)$ & $\begin{array}{l}174 \\
(100)\end{array}$ \\
\hline
\end{tabular}

Table 2. Distribution of special incidents by different seasons, Iran in 2014

\begin{tabular}{|c|c|c|c|c|c|c|}
\hline \multirow{2}{*}{\multicolumn{2}{|c|}{ Type of incident }} & \multicolumn{4}{|l|}{ Season } & \multirow{3}{*}{$\begin{array}{l}\text { Total } \\
4812(100) \\
\end{array}$} \\
\hline & & \multirow{2}{*}{$\begin{array}{l}\text { Spring } \\
1292(27)\end{array}$} & \multirow{2}{*}{$\begin{array}{l}\text { Summer } \\
1447(30)\end{array}$} & \multirow{2}{*}{$\begin{array}{l}\text { Autumn } \\
1078(22)\end{array}$} & \multirow{2}{*}{$\begin{array}{l}\text { Winter } \\
995(21)\end{array}$} & \\
\hline Road traffic crashes & $\mathrm{n}(\%)$ & & & & & \\
\hline & $\%$ within season & 79 & 81 & 66 & 57 & 71 \\
\hline \multirow[t]{2}{*}{ CO poisoning } & $\mathrm{n}(\%)$ & $88(9)$ & $10(1)$ & $355(37)$ & $508(53)$ & $961(100)$ \\
\hline & $\%$ within season & 5 & 1 & 22 & 29 & 14 \\
\hline \multirow[t]{2}{*}{ Explosion } & $\mathrm{n}(\%)$ & $48(30)$ & $33(20)$ & $29(18)$ & $53(32)$ & $163(100)$ \\
\hline & $\%$ within season & 3 & 2 & 2 & 3 & 2.5 \\
\hline \multirow[t]{2}{*}{ Unexplained death } & $\mathrm{n}(\%)$ & $28(15)$ & $37(20)$ & $65(35)$ & $56(30)$ & $186(100)$ \\
\hline & $\%$ within season & 2 & 2 & 4 & 3 & 3 \\
\hline \multirow[t]{2}{*}{ Drowning } & $\mathrm{n}(\%)$ & $69(29)$ & $140(59)$ & $19(8)$ & $8(4)$ & $236(100)$ \\
\hline & $\%$ within season & 4 & 8 & 1 & 0.5 & 3.5 \\
\hline \multirow[t]{2}{*}{ Group poisoning } & $\mathrm{n}(\%)$ & $42(30)$ & $33(24)$ & $29(21)$ & $35(25)$ & $139(100)$ \\
\hline & $\%$ within season & 3 & 2 & 2 & 2.5 & 2 \\
\hline \multirow[t]{2}{*}{ Fall from height } & $\mathrm{n}(\%)$ & $17(38)$ & $13(29)$ & $7(15)$ & $8(18)$ & $45(100)$ \\
\hline & $\%$ within season & 1 & 1 & 0.4 & 0.5 & 0.5 \\
\hline \multirow[t]{2}{*}{ Fire } & $\mathrm{n}(\%)$ & $16(17)$ & $27(29)$ & $18(20)$ & $31(34)$ & $92(100)$ \\
\hline & $\%$ within season & 1 & 1 & 1 & 2 & 1.5 \\
\hline \multirow[t]{2}{*}{ Quarrel } & $\mathrm{n}(\%)$ & $25(27)$ & $26(28)$ & $21(22)$ & $22(23)$ & $94(100)$ \\
\hline & $\%$ within season & 1 & 1 & 1 & 1.5 & 1.5 \\
\hline \multirow[t]{2}{*}{ Building collapse } & $\mathrm{n}(\%)$ & $15(28)$ & $11(21)$ & $12(23)$ & $15(28)$ & $53(100)$ \\
\hline & $\%$ within season & 1 & 1 & 0.6 & 1 & 0.5 \\
\hline \multirow[t]{2}{*}{ Total } & $\mathrm{n}(\%)$ & $1640(24)$ & $1777(26)$ & $1633(24)$ & $1731(26)$ & $6781(100)$ \\
\hline & $\%$ within season & 100.0 & 100.0 & 100.0 & 100.0 & 100.0 \\
\hline
\end{tabular}




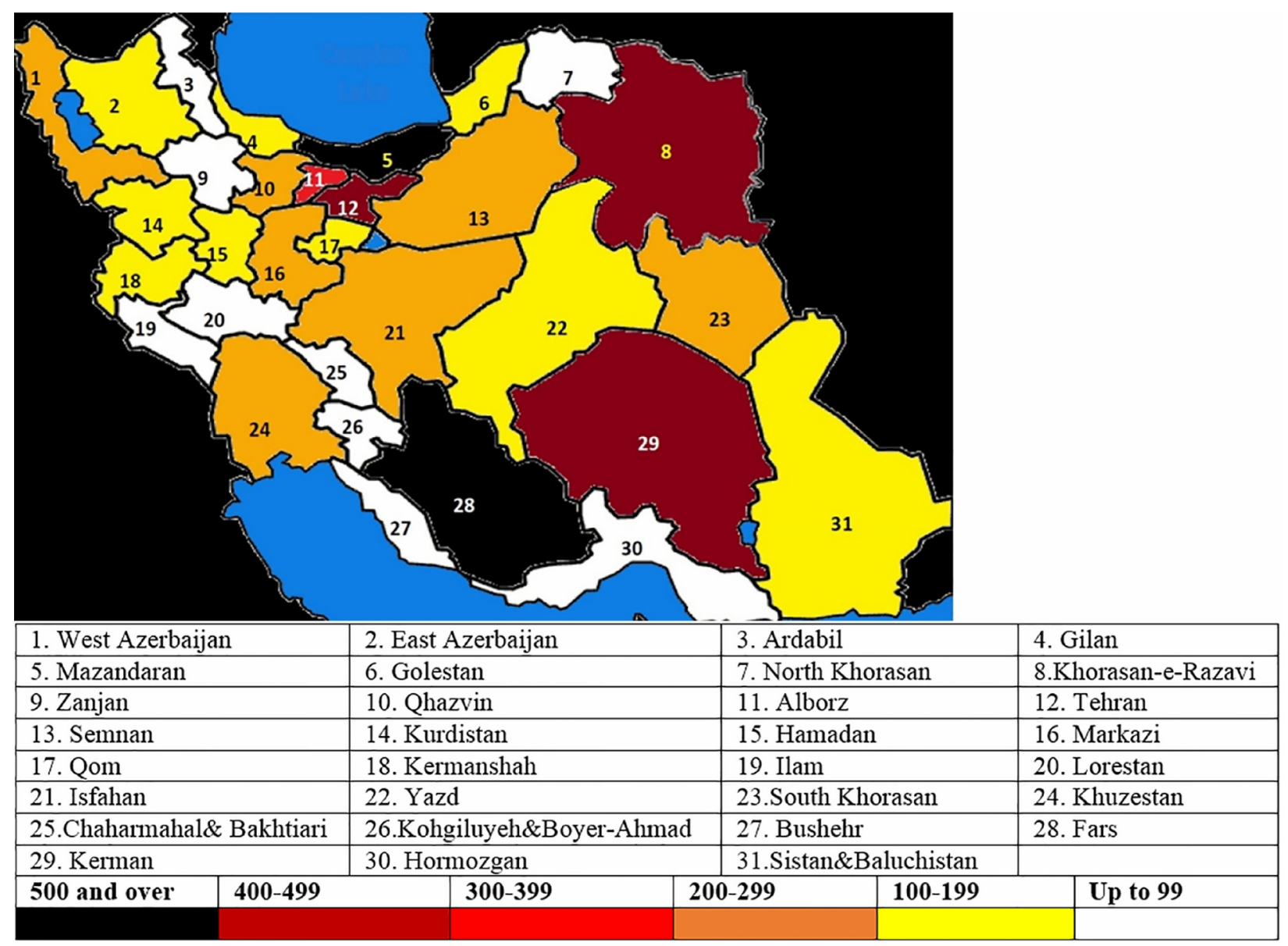

Figure 1. Frequency of special incidents across Iran's provinces in 2014

In the present study, particular attention was paid to special traffic incidents because they were the most common special incidents in Iran. The total number of special traffic crashes (crashes with more than two deaths or 4 casualties) during 2014 was 4,812 cases, which led to 2,459 deaths (14\% of the total RTIs in 2014) and 29,190 casualties (9.6\% of total all RTI casualties), of whom 27,677 cases were transferred to hospital and 1,513 were cases of minor injuries. Of these 2,459 deaths, $90.5 \%$ died before arrival of the ambulances, $1 \%$ died in the presence of an EMS technician, 3\% died during transfer to hospital, and 5.5\% died in hospital. In terms of EMS response time, the shortest was one minute and the longest 90 minutes (Mean= 8, SD= 6 minutes). A significant relationship was found between response time and number of deaths (before ambulance arrival, in the presence of an EMS technician, during transfer to hospital, and in the hospital), such that longer response time increased chances of death (Table 4). In terms of geographical distribution, the majority of special traffic incidents happened in Fars province, followed by Kerman and Mazandaran provinces, and the least number of crashes occurred in North Khorasan province. According to the Ministry of Interior's division of neighboring provinces into 5 zones, most special traffic crashes occurred in zone 1 (27\%) including Tehran, Qazvin, Mazandaran, Semnan, Golestan, Alborz, and Qum provinces; followed by zone 5 (23\%) (Including Khorasan-Razavi, South Khorasan, North Khorasan, Kerman, Yazd and Sistan-Baluchistan provinces), and the least RTIs were in zone 3 (12\%) including East and West Azerbaijan, Ardabil, Zanjan, Gilan and Kurdistan provinces. However, based on the provincial population, the most special traffic incidents happened in Semnan province, followed by South Khorasan, and the least occurred in Tehran province (Figure 2). In terms of season, $30.1 \%$ of special traffic incidents occurred in summer and $26 \%$ in spring. However, these incidents happened less frequently in winter (20\%). Moreover, most special traffic incidents had happened on Iran's weekend; Fridays (20\%), and Thursdays (that is an official holiday in some provinces) (15\%). The least special traffic incidents happened on Mondays (11\%). These events increased during the weekend, as the findings showed for all special incidents. Distribution of special traffic incidents in terms of hours of the day showed that most of these crashes occurred during 12:00-17:59 (35\%), followed by 18:00-23:59 (29.1\%) and 06:00-11:59 $(22 \%)$, and the least, during 00:00-05:59 (13.1\%). The leading month for occurrence of these crashes was 
http://www.ephysician.ir

March/April (12\%), which coincides with Nowruz holidays, followed by September (11.9\%), and the least number of incidents occurred in January (6\%). Results regarding holiday RTIs, were as follows: The majority happened during weekends $(34 \%)$, followed by Nowruz holidays $(7 \%)$, and the least number of such incidents happened during official days $(4 \%)$.

Table 3. The occurrence of special incidents across working and non-working days in Iran in 2014

\begin{tabular}{|l|l|l|l|l|}
\hline Statistics & $\begin{array}{l}\text { Working days } \\
(242 \text { days })\end{array}$ & $\begin{array}{l}\text { Nowruz holidays } \\
(6 \text { days })\end{array}$ & $\begin{array}{l}\text { Weekends (104 } \\
\text { days) }\end{array}$ & $\begin{array}{l}\text { Other official } \\
\text { holidays (13 days) }\end{array}$ \\
\hline Special incidents; $\mathrm{n}(\%)$ & $3727(55)$ & $464(7)$ & $2297(34)$ & $293(4)$ \\
\hline Special traffic events; $\mathrm{n}(\%)$ & $2592(54)$ & $366(8)$ & $1647(34)$ & $207(4)$ \\
\hline $\begin{array}{l}\text { Average special traffic } \\
\text { incidents per day }\end{array}$ & 15 & 77 & 22 & 22 \\
\hline $\begin{array}{l}\text { Average special traffic } \\
\text { incidents per day }\end{array}$ & 11 & 61 & 16 & 16 \\
\hline
\end{tabular}

Table 4. Relationship between response time and number of deaths in specific RTIs in Iran in 2014

\begin{tabular}{|l|l|l|l|l|l|}
\hline Statistics & $\begin{array}{l}\text { Total } \\
\text { death }\end{array}$ & $\begin{array}{l}\text { Death before } \\
\text { arrival }\end{array}$ & $\begin{array}{l}\text { Death in presence } \\
\text { of EMS }\end{array}$ & $\begin{array}{l}\text { Death during transfer to } \\
\text { hospital }\end{array}$ & $\begin{array}{l}\text { Death in the } \\
\text { hospital }\end{array}$ \\
\hline $\begin{array}{l}\text { Pearson } \\
\text { correlation }\end{array}$ & 0.028 & 0.032 & -0.008 & 0.001 & -0.014 \\
\hline p-value & 0.051 & 0.025 & 0.000 & 0.000 & 0.000 \\
\hline
\end{tabular}

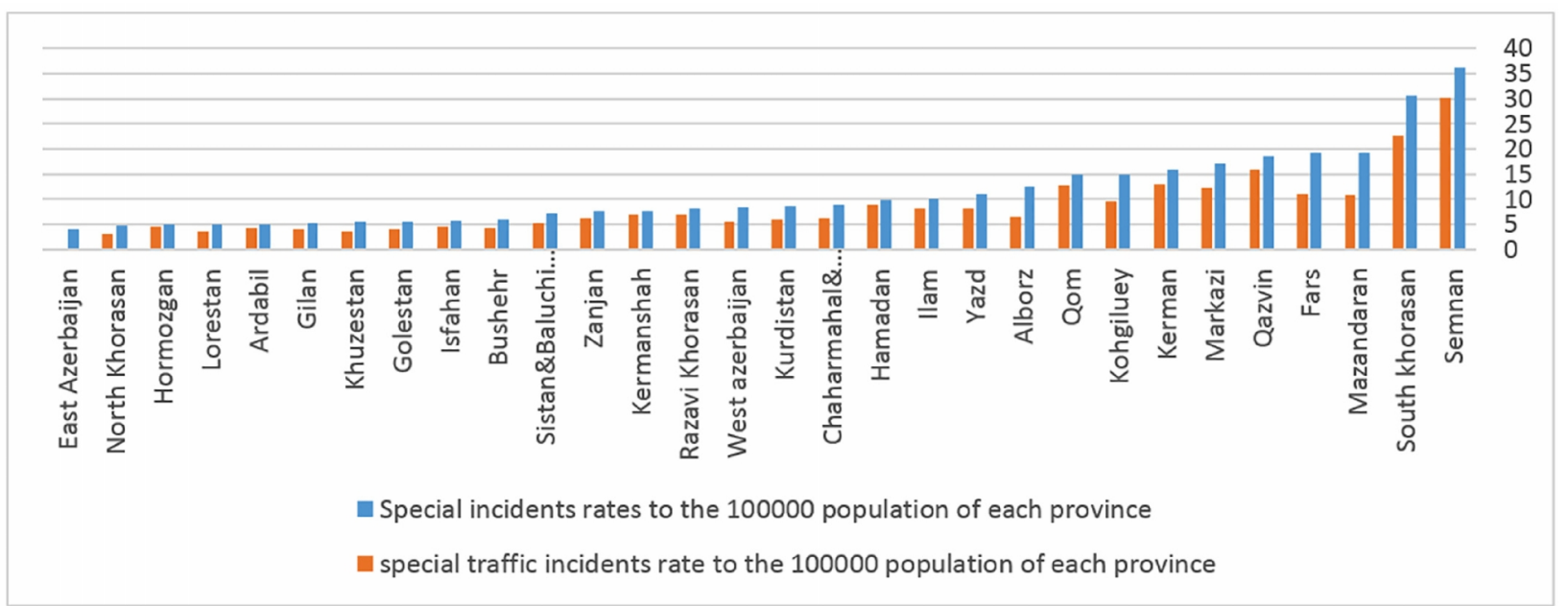

Figure 2. Distribution of special incidents and special traffic incidents per 100,000 population across Iranian Provinces, 2014 (horizontal axis: provinces, vertical axis: number of accidents)

\section{Discussion}

During 2014, 6,781 special incidents occurred in Iran, of which, approximately $71 \%$ of total special incidents, $75 \%$ of total deaths from special incidents and $78 \%$ of all casualties were due to traffic incidents. They mostly happened in March/April, and least in January. Many incidents happened on Fridays and the least of them on Mondays. In general, the lowest prevalence of special incidents was in the month of Ramadan ((fasting month for Muslims)) $(6 \%)$. In the present study, the monthly mean number of special incidents was 565 cases per month. This was 73 cases per month in Pakistan (4), 26.6 cases in South Korea (20), 11 cases per month in Cape Town (South Africa) (21), 4 cases per 12 years in Kenya (22), 3 to 4 cases per year over a 28-year period in Britain (23), and 433 cases per month in 7 states of America in 2010 (24). There are several possible reasons for such major differences between various countries. First, there is no internationally agreed standard definition for special incidents because our search for special incidents in other countries did not give us any results. As explained earlier, each country has its own definition. Second, the registration system of special events might have different sensitivity on the incidents and consequently, some special incidents are probably missed in some countries. In the present study, special traffic incidents make up $71 \%$ of the total number of incidents. This was $94 \%$ in South Africa (21), 78.6\% in South Korea 
(20), 59.2\% in Britain (23), 48.6\% in Pakistan (4), and 62.7\% in Finland (25). Again, the difference can be attributed to the definition of special incidents used in different studies. Nevertheless, where road safety factors, including humans, roads and cars are under strict control, we may expect less share of traffic crashes as special incidents. In the current study, more than three quarters (78\%) of casualties of special incidents were caused by RTIs. This amount was $73.7 \%$ in Pakistan (4), 79.9\% in South Korea (20) and 62.7\% in Finland (25), which was similar to our study, but it was $90.6 \%$ in South Africa (21). This difference in South Africa may be due to the higher number of incidents, and more than $40 \%$ of traffic incidents involved minibuses, which leave behind a greater number of casualties per accident (21). Unlike the study conducted in Pakistan, which showed higher RTIs in more densely populated regions (4), such a pattern did not exist in the present study, such that although Tehran's population density is 144 times of that in Semnan's, its number of traffic crashes was only twice as Semnan's. The higher number of RTIs in Semnan can be due to its location on the highway connecting the East of the country to the capital city, Tehran. The prevalence of traffic incidents was the highest on Fridays and the lowest on Mondays, which may be due to the fact that Friday is part of the weekend holiday in Iran, and also the Government offices and organizations are not working on Thursdays in most provinces, making the greater number of weekend trips possible. It is also important to note that culturally many Iranian people make trips for entertainment and more than $90 \%$ of their trip is by vehicle and not by air or rail $(26,27)$. It can be as an important result for a high proportion of such incidents. Similar observation was made by others (28); in which they found the highest occurrence of RTIs on Sundays (weekend) and lowest on Mondays. This finding is again similar with another study which was made in California in which they found the highest RTI occurrence on weekends (Saturdays) (29). The highest number of traffic incidents happened during March/April, followed by September, and the lowest during January, which may be due to increased number of journeys during Nowruz and summer holidays, which is similar with other studies in Iran (11). The lower number of RTIs in winter does not imply lower risk of incidents; but merely lower crude number of incidents. However, the likelihood of crashes per journey cannot be extracted from these data. CO poisoning was most prevalent in January and least in June, which can be attributed to greater use of gas heaters and other non-central heating facilities in winter. Similarly, in another study in America, CO poisoning had the highest rate in January and the lowest rate in July (34). This mainly happened in countryside and rural areas, which is an important implication for replacement of gas heaters by safer devices such as radiators in Iran. The highest number of drownings was in summer and the lowest in winter. Moreover, $44 \%$ of drowning cases happened in Mazandaran province. Given that coastal provinces of the north are the main destination for summer travelers in Iran, where the temperature is much lower than southern coasts, increased drowning is due to the increased number of journeys as well as unsafe and unsupervised coastlines. A similar finding was observed that $72.2 \%$ of drowning occurred at unprotected beaches of Iran, and $91 \%$ of drowning happened in summer, $65.9 \%$ of them were travelers (30). The least number of RTIs occurred during the month of Ramadan (6\%), which can be due to reduced traffic on the roads and the effect of religious teachings in reducing crime or observing safety points. It is important to note that based on Ramadan rules, a trip of more than 22 kilometers can invalidate Muslim fasting, so people mainly choose to stay at their own town. Additional reasons may be causes for prevention of RTIs which need more investigation. This finding is different from some studies conducted across other Islamic nations $(31,32)$. They reported a higher incidence of RTIs during Ramadan than other months. In proportion to the population, the lowest incidents occurred in Tehran province, which can be due to higher standards on safety factors and high socioeconomic status. Similar findings were found by other studies that incidence of traffic crashes is lower in high socio-economic levels (33).

\section{Strengths and limitations}

Nationwide data for this study and including all special events across the country is one of the strengths of this study. In addition, mandatory, immediate and systemic registration of these incidents increased data accuracy.

Limitations of this study include lack of information on vehicle type, age and educational level of victims and driver, weather conditions and injury and crash mechanism which prevents better interpretation of other factors on the occurrence of injuries, deaths and disabilities.

\section{Conclusions}

Because of the increased number of special incidents, particularly, traffic crashes, during holidays (especially Nowruz holidays), greater monitoring and control by relevant organizations is essential. In addition, given the pattern of incidents and its relationship with different seasons and months, preventive and training programs should be organized and implemented according to the month and type of incidents. It is recommended that in addition to collection of routine data, a full incidents report containing such data as type of vehicle, age, gender and education of casualties and driver, type of road (urban, rural, highway, freeway), weather conditions, the nearest emergency base, age, cause of incidents and number of casualties transferred by non-ambulance vehicles should also be 
recorded, so that these incidents can be monitored annually by creating a systematic arrangement, and results should be used in national and regional planning.

\section{Acknowledgments:}

We want to give acknowledgment to the Emergency Operation Center of the Ministry of Health and Medical Education for their assistance with providing basic information. This study was part of a Ph.D. dissertation, supported and sponsored by Iran University of Medical Sciences.

\section{Conflict of Interest:}

There is no conflict of interest to be declared.

\section{Authors' contributions:}

JB was involved in design of study, data collection, data analysis and interpretation of the data as well as drafting of final manuscript. DKZ and AA were involved in conception and design of the study, statistical analysis and offered a critical review of the manuscript for intellectual content. All the authors have read and approved the final version of the manuscript.

\section{References:}

1) Herbosa TJ, Lam HY, Andrew P, Zambrano G. Mass casualty management (MCM) system assessment in the Western Pacific Region. Southeast Asian Journal of Tropical Medicine and Public Health. 2009; 40(1): 47-56.

2) World Health Organization. Mass Casualty Management System: strategies and guidlines for health sector capacity. Geneva: WHO publisher; 2007.

3) Cook L. The World Trade Center attack. The paramedic response: an insider's view. Crit Care. 2001; 5(6): 301-3. PMID: 11737911, PMCID: PMC137373.

4) Waseem H, Carenzo L, Razzak J, Naseer R. Epidemiology of major incidents: an EMS study from Pakistan. Int J Emerg Med. 2011; 4: 48. doi: 10.1186/1865-1380-4-48. PMID: 21798011, PMCID: PMC3158548.

5) Hamidreza Kkankeh and co-authors. Disaster Hospital Preparedness: National Plan. Iran: University of Social Welfare and Rehabilitation Publisher; 2013.

6) Operation assistant of disaster and emergency management center: Occurance 11.5 MCI in IRAN daily 2015. In: Iranian Students' News Agency. 2015.

7) Ministry of Health and Medical Education. List of reportable special incidents. Available from: http://health.abzums.ac.ir/portal/file/?41661/\%D8\%AD\%D9\%88\%D8\%A7\%D8\%AF\%D8\%AB$\%$ D9\%88\%D9\%8A\%DA\%98\%D9\%87.pdf.

8) Khorasani Zavareh D, Mohammadi R, Laflamme L, Naghavi M, Zarei A, Haglund BJ. Estimating road traffic mortality more accurately: use of the capture-recapture method in the West Azarbaijan province of Iran. Int J Inj Contr Saf Promot. 2008; 15(1): 9-17. doi: 10.1080/17457300701794105. PMID: 18344091.

9) World Health Organization. Global status report on road safety 2013: Supporting a decade of action. World Health Organization; 2013.

10) World Health Organization. Global status report on road safety 2015. World Health Organization; 2015.

11) Khorasani-Zavareh D, Haglund BJ, Mohammadi R, Naghavi M, Laflamme L. Traffic injury deaths in West Azarbaijan province of Iran: a cross-sectional interview-based study on victims' characteristics and prehospital care. Int J Inj Contr Saf Promot. 2009; 16(3): 119-26. doi: 10.1080/17457300903023980. PMID: 19941209.

12) Ainy E, Soori H, Ganjali M, Le H, Baghfalaki T. Estimating cost of road traffic injuries in Iran using willingness to pay (WTP) method. PloS One. 2014; 9(12): e112721. doi: 10.1371/journal.pone.0112721. PMID: 25438150, PMCID: PMC4249801.

13) Khorasani-Zavareh D, Khankeh HR, Mohammadi R, Laflamme L, Bikmoradi A, Haglund BJ. Post-crash management of road traffic injury victims in Iran. Stakeholders' views on current barriers and potential facilitators. BMC Emerg Med. 2009; 9: 8. doi: 10.1186/1471-227X-9-8. PMID: 19435521, PMCID: PMC2692975.

14) Rezaei S, Akbari-Sari A, Arab M. Estimating hospital costs and other health services expenses of road traffic crashes in iran, 2009. Hakim. 2013; 16(3): 192-200.

15) Iran Sco. Statistical Yearbook- Selected findings of the 2011 national population and housing census In. Iran: Statistical center of Iran; 2011. 
16) Haghparast-Bidgoli $\mathrm{H}$, Hasselberg $\mathrm{M}$, Khankeh $\mathrm{H}$, Khorasani-Zavareh D, Johansson E. Barriers and facilitators to provide effective pre-hospital trauma care for road traffic injury victims in Iran: a grounded theory approach. BMC Emerg Med. 2010; 10: 20. doi: 10.1186/1471-227X-10-20. PMID: 21059243, PMCID: PMC2992044.

17) Khankeh HR, Khorasani-Zavareh D, Johanson E, Mohammadi R, Ahmadi F. Disaster health-related challenges and requirements: a grounded theory study in Iran. Prehosp Disaster Med. 2011; 26(3): 151-8. doi: 10.1017/S1049023X11006200. PMID: 21929828.

18) Ardalan A, Masoomi G, Goya M, Ghaffari M, Miadfar J, Sarvar M, et al. Disaster health management: Iran's progress and challenges. Iranian Journal of Public Health. 2009; 38(Suppl 1): 93-7.

19) Education MoHaM. Reportable special events. In. Edited by Centre DaEM. Iran: Disaster and Emergency Management Centre; 2015.

20) Kim SJ, Kim CH, Shin SD, Lee SC, Park JO, Sung J. Incidence and mortality rates of disasters and mass casualty incidents in Korea: a population-based cross-sectional study, 2000-2009. J Korean Med Sci. 2013; 28(5): 658-66. doi: 10.3346/jkms.2013.28.5.658. PMID: 23678255, PMCID: PMC3653076.

21) van Hoving DJ, Lategan HJ, Wallis LA, Smith WP. The epidemiology of major incidents in the Western Cape Province, South Africa. S Afr Med J. 2015; 105(10): 831-4. doi: 10.7196/SAMJNEW.7766. PMID: 26428587.

22) Wachira BW, Smith W. Major incidents in Kenya: the case for emergency services development and training. Prehosp Disaster Med. 2013; 28(2): 170-3. doi: 10.1017/S1049023X13000010. PMID: 23388493.

23) Carley S, Mackway-Jones K, Donnan S. Major incidents in Britain over the past 28 years: the case for the centralised reporting of major incidents. J Epidemiol Community Health. 1998; 52(6): 392-8. doi: 10.1136/jech.52.6.392. PMID: 9764261, PMCID: PMC1756719.

24) Schenk E, Wijetunge G, Mann NC, Lerner EB, Longthorne A, Dawson D. Epidemiology of mass casualty incidents in the United States. Prehosp Emerg Care. 2014; 18(3): 408-16. doi: 10.3109/10903127.2014.882999. PMID: 24673664.

25) Kuisma M, Hiltunen T, Maatta T, Puolakka J, Boyd J, Nousila-Wiik M, et al. Analysis of multiple casualty incidents - a prospective cohort study. Acta Anaesthesiol Scand. 2005; 49(10): 1527-33. doi: 10.1111/j.1399-6576.2005.00761.x. PMID: 16223401.

26) Khorasani-Zavareh D, Mohammadi R, Khankeh HR, Laflamme L, Bikmoradi A, Haglund BJ. The requirements and challenges in preventing of road traffic injury in Iran. A qualitative study. BMC Public Health. 2009; 9: 486. doi: 10.1186/1471-2458-9-486. PMID: 20030826, PMCID: PMC2811114.

27) Khorasani-Zavareh D. System versus traditional approach in road traffic injury prevention: a call for action. J Inj Violence Res. 2011; 3(2): 61. doi: 10.5249/jivr.v3i2.128. PMID: 21498966, PMCID: PMC3134927.

28) Jha N, Srinivasa D, Roy G, Jagdish S, Minocha R. Epidemiological study of road traffic accident cases: A study from South India. Indian J Community Med. 2004; 29(1): 20-4.

29) Stallones RA, Corsa L. Epidemiology of childhood accidents in two California counties. Public Health Rep. 1961; 76(1): 25-36. doi: 10.2307/4591054. PMID: 19316377, PMCID: PMC1929592.

30) Saberi Anary SH, Sheikhazadi A, Ghadyani MH. Epidemiology of drowning in Mazandaran province, north of Iran. Am J Forensic Med Pathol. 2010; 31(3): 236-42 doi: 10.1097/PAF.0b013e3181e804de. PMID: 20548217.

31) Roky R, Houti I, Moussamih S, Qotbi S, Aadil N. Physiological and chronobiological changes during Ramadan intermittent fasting. Ann Nutr Metab. 2004; 48(4): 296-303. doi: 10.1159/000081076. PMID: 15452402.

32) Tahir MN, Macassa G, Akbar AH, Naseer R, Zia A, Khan S. Road traffic crashes in Ramadan: an observational study. Eastern Mediterranean health journal. 2014; 19 Suppl 3: S147-51.

33) Sehat M, Naieni KH, Asadi-Lari M, Foroushani AR, Malek-Afzali H. Socioeconomic Status and Incidence of Traffic Accidents in Metropolitan Tehran: A Population-based Study. Int J Prev Med. 2012; 3(3): 18190. PMID: 22448311, PMCID: PMC3309632.

34) Sircar K, Clower J, kyong Shin M, Bailey C, King M, Yip F. Carbon monoxide poisoning deaths in the United States, 1999 to 2012. Am J Emerg Med. 2015; 33(9): 1140-5. doi: 10.1016/j.ajem.2015.05.002. PMID: 26032660, PMCID: PMC4573527. 